\title{
Renewable, local electricity generation from palm oil mills: a case study from Peninsular Malaysia
}

\author{
Ida Fahani Md Jaye, Jhuma Sadhukhan, Richard J. Murphy* \\ Centre for Environmental Strategy, Faculty of Engineering \& Physical Sciences, University of Surrey, Guildford GU2 7XH,UK
}

\begin{abstract}
The generation of electricity from fossil fuels is a major emitter of greenhouse gas (GHG) and other atmospheric emissions in Malaysia. With an average of $0.77 \mathrm{~kg} \mathrm{CO}_{2} / \mathrm{kWh}$ and amounts of trace gasses emitted from electrical power generation, Malaysia is subject to associated adverse effects of global warming, acidification and urban smog. Mitigation of these negative consequences by incorporating renewable energy resources into the national power generation mix is a goal of the 2010 National Renewable Energy Policy and in this context, we have begun to explore the potential for local sources of small-scale 'green electricity' generation as a feasible option for the supply of renewable electricity. Such generation plants could use the abundant resources of Empty Fruit Bunches (EFBs) and Palm Oil Mill Effluents (POMEs) from Palm Oil (PO) mills. In our modelling, the surplus energy potential of an exemplar generation plant was scaled to the available surplus biomass resources of a PO mill and to the local demand of the number of local domestic users that could potentially be supplied. The potential reductions in environmental impacts and the level of Certified Emission Reduction (CER) from implementation of the proposed plant in comparison with conventional average grid supply were also assessed. The proposed surplus electricity generation from the PO mill was more than adequate to supply the estimated 2620 domestic users within a notional $10 \mathrm{~km}$ radius of the mill and could avoid approx. 6000 tonnes $\mathrm{CO}_{2 \mathrm{e}}$ per annum from centrally generated electricity for these homes. This prospect also offers a solution for optimising the uses of the mill's biomass residues.
\end{abstract}

Keywords: Global warming, renewable electricity, distributed generation, palm oil mill, anaerobic digestion, combustion

\section{Introduction}

Providing adequate, affordable and clean electricity is a modern necessity. For an upper middle income country like Malaysia with the potential of becoming a high income country in 2020, it is important to harness a secure, reliable electricity supply to drive economic growth, preserve the environment and maintain price competitiveness. The maximum grid demand in Peninsular Malaysia was recorded at 16,562 MW in 2013 while the annual electricity demand was 112,358 GWh. Electricity sales were $100,999 \mathrm{GWh}$ with the generation reserve margin of $10 \%$. The generation reserve margin may diminish if no short to medium term actions are taken to increase generation capacity and production. Coal and natural gas are the dominant fuels for electricity generation in Malaysia and this is the major carbon emitter in the country [1]. As a signatory to the Kyoto Protocol in 1998, Malaysia has pledged to reduce greenhouse gas (GHG) emissions to mitigate global climate change. To demonstrate the commitment towards preserving the environment, the Prime Minister proposed to reduce the national $\mathrm{CO}_{2}$ emission by $40 \%$ from the 2005 level by 2020 at the Fifteenth session of the Conference of the Parties (COP 15). With this substantial commitment, transition to a low carbon electricity and low fossil fuel electricity is very important to enable Malaysia to reduce its $\mathrm{CO}_{2}$ emission from electricity generation [2]. In the same study, it was stated that each of the economic sectors has to reduce the amount of $\mathrm{CO}_{2}$ production at the rate of

\footnotetext{
* Manuscript received October 20, 2015; revised April 20, 2016.

Corresponding author. Tel.:+44(0)14836866680; E-mail address: rj.murphy@ surrey.ac.uk.

doi: $10.12720 /$ sgce.5.2.106-111
} 
$4 \%$ each year. This was made evident in $9^{\text {th }}$ Malaysia Plan when the Government emboldened the power provider to reduce the reliance on fossil fuels for electricity generation [3]. The enthusiasm to reduce $\mathrm{CO}_{2}$ emissions was indisputable when the Malaysian Green Technology Corporation (GreenTech Malaysia) was set up under the jurisdiction of the Ministry of Energy, Green Technology and Water to catalyse the adoption of green technology in Malaysia. GreenTech Malaysia plays a significant role in facilitating the National Green Technology Policy and National Biomass Strategy 2020 that aims to revolutionize the electricity supply chain to a Zero Carbon Electricity (ZCE) and Renewable Energy Electricity (REE).

In addition to the plans and policies for sustainable electricity, the Malaysian Government has sought to invest in an alternative electricity supply network, which also has the potential to achieve a more resilient system. The National Key Economic Area for palm oil industries under the Economic Transformation Programme, aims to achieve the installation of biogas facilities in all PO mills in Malaysia by 2020 . With the strong support from the Government, diversification in the potential of ZCE and REE has been made feasible.

\section{Methodology}

Residues like Empty Fruit Bunches (EFBs) and Palm Oil Mill Effluent (POME) are by-products from the PO industry that offer potentially favourable options to substitute fossil fuels for electricity generation. Due to their availability throughout the year, their 'carbon neutral' properties vis-a-vis greenhouse gas (GHG) emissions and their energy content, their direct combustion and/or Anaerobic Digestion (AD) to produce heat and electricity is feasible. However, all too often such residues are regarded as inconvenient waste, disposed of in the environment and their utilization rate is negligible. It is estimated that for each tonne of Fresh Fruit Bunch (FFB) processed $220 \mathrm{~kg}$ of Empty Fruit Bunch (EFB), $55 \mathrm{~kg}$ Palm Kernel Shell (PKS), $130 \mathrm{~kg}$ fibre and $650 \mathrm{~kg}$ Palm Oil Mill Effluent (POME) are produced as residues [4]. EFB and POME are the by-products with the highest potential for generating electricity. The high lignin content of EFB and combustible properties of methane $\left(\mathrm{CH}_{4}\right)$ from the AD of POME are particularly relevant for this purpose [5]. At present, the main routes for the management of surplus EFB and POME are soil amendment for approx. $61 \%$ of EFB produced while methane produced from POME treatment is mainly flared to $\mathrm{CO}_{2}$ and released to atmosphere [6].

This paper presents a resource and environmental scoping assessment of the potential to develop a locally-based, decentralized, electricity generation capability to deliver renewable electricity to the Malaysian grid. In a case-study approach we have modelled the power generation potential from a single PO mill based on the availability of its EFB residue and the methane yield from the AD of its POME for the year 2014. The estimated values are then compared against the actual electricity demand of the surrounding communities to gauge the supply scale that could be achieved. The potential of this localised generation from the case study PO mill to reduce the supply burden on the national grid was then modelled to indicate potential emissions and environmental impact savings from avoided central generation together with an estimate of the number of consumers that could benefit from this renewable electricity supply. The amount of GHG emission reduction is a key parameter of this potential new supply and is evaluated for its potential for carbon credits under the Clean Development Mechanism (CDM).

The data for this case study was obtained in cooperation with the small scale Bell Sri Lingga PO mill at Kuala Linggi, Melaka and from the Tenaga Nasional Masjid Tanah Branch Office. The Bell Sri Lingga Sdn Bhd mill is located at Batu 32, Kampung Kuala Linggi, 78200, Kuala Sungai Baru, Melaka, Peninsular Malaysia. Fig. 1 and Fig. 2 shows the physical location of the selected mill. The mill has underutilised by-products, undertakes flaring of its POME AD biogas and is interested in improved management options for its residues and emissions.

The mill has a 24 hour per day operation capacity, 6 days per week throughout the year. On average, it is operated 14 hours per day, 240 days per year due to its FFB inputs, general maintenance, breakdown and annual closure days. The mill has a processing capacity of 35 tonnes fresh fruit bunch (FFB) per hour and obtains its FFB from small suppliers and traditional plantations nearby. Table 1 summarizes the production capacity of the mill in 2014. 


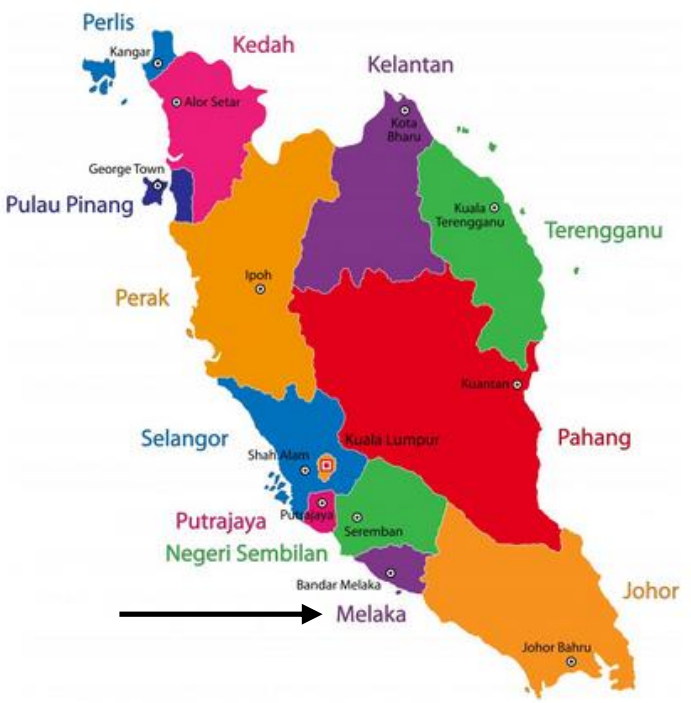

Fig. 1. Map of Peninsular Malaysia [7].

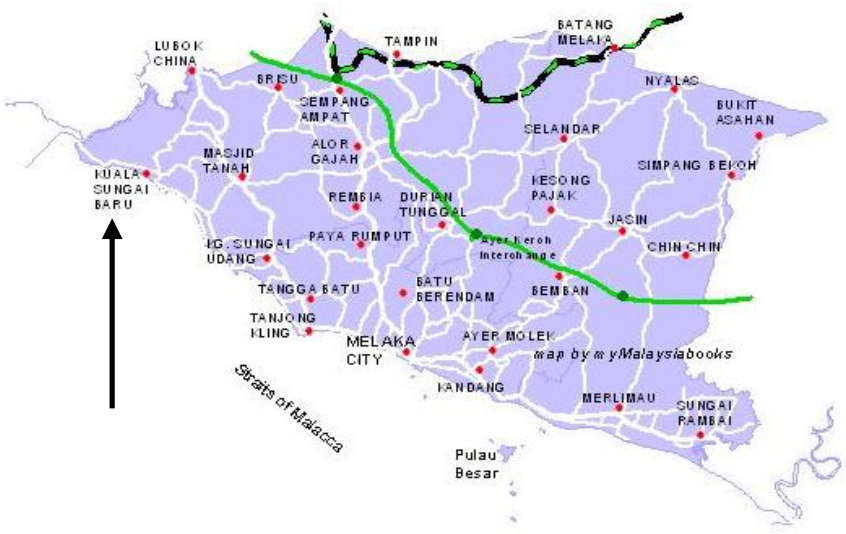

Fig. 2. Map of Kuala Sungai Baru [8].

Table 1. 2014 Mill Production Capacity

\begin{tabular}{lr}
\hline Products & Amount (tonnes/yr) \\
\hline FFB processed & 115,660 \\
Crude Palm Oil (CPO) produced & 21,380 \\
POME produced & 69,395 \\
EFB produced & 27,758 \\
\hline
\end{tabular}

The complete POME treatment in the mill consists of 2 anaerobic digesters each $4000 \mathrm{~m}^{3}, 4$ anaerobic ponds, 2 aerobic ponds and 6 evaporation ponds. The digester efficiency is $85 \%$ with a feeding rate of $10,500 \mathrm{~kg}$ per hour and a biogas flow rate of $400-600 \mathrm{~m}^{3}$ per hour. The digestate produced is sold as fertilizer and the waste water is sent to the evaporation ponds. Currently, the biogas that has been captured is flared to atmosphere. At present, EFBs are composted informally in heaps which uses a lot of space.

\section{Result and Discussion}

\subsection{Power generation potential}

The power generation potential can be estimated from the EFB and POME production data in Table 1. 
The estimated power generation from POME biogas (Table 2) is based on the guidelines provided by the National Biogas Implementation programme (EPP 5) of the Performance Management \& Delivery Unit (PEMANDU) and the estimated power generation from EFB (Table 3) is based on the methodologies laid out by the Malaysian Palm Oil Board.

Table 2. Estimated power generation from POME biogas combustion [9]

\begin{tabular}{lll}
\hline Parameters & Rate $^{\text {a }}$ & Amount \\
\hline POME & $28 \mathrm{~m}^{3} / \mathrm{m}^{3} \mathrm{POME}$ & $69,395 \mathrm{~m}^{3} / \mathrm{yr}$ \\
Biogas & $20 \mathrm{MJ} / \mathrm{m}^{3}$ biogas & \\
Calorific Value (CV) biogas @ 35 $5^{\circ} \mathrm{C}$ & & $38,861,452 \mathrm{~mJ} / \mathrm{yr}$ \\
Heat Value & & $10,795 \mathrm{MWh} / \mathrm{yr}$ \\
& $21 \%$ of heat value & $2267 \mathrm{MWh} / \mathrm{yr}$ \\
Output Power & 300 days/yeat & $0.31 \mathrm{MW}$ \\
Power Plant Size & & \\
${ }^{2}$ From POME Fact Sheet for the Malaysian Palm Oil Industry &
\end{tabular}

Table 3. Estimated power generation from EFB combustion [10]

\begin{tabular}{lll}
\hline Parameters & Rate $^{\text {a }}$ & Amount \\
\hline EFB & & 27,758 tonnes/yr \\
Dried EFB & $35 \%$ total weight & $\begin{array}{l}9,715 \text { tonnes/yr } \\
9,715,398 \mathrm{~kg} / \mathrm{yr}\end{array}$ \\
& & \\
Calorific Value (CV) EFB & $18.96 \mathrm{MJ} / \mathrm{kg}$ & $184,203,946 \mathrm{MJ} / \mathrm{yr}$ \\
Heat Value & & $51,168 \mathrm{MWh} / \mathrm{yr}$ \\
& $25 \%$ of heat value & $12,792 \mathrm{MWh} / \mathrm{yr}$ \\
Output Power & 300 days/yeat & $1.78 \mathrm{MW}$ \\
Power Plant Size &
\end{tabular}

The total output power that can be generated from EFB and POME biogas combustion at the mill is 15,059 MWh. Thus, a power plant capacity of $2 \mathrm{MW}$ can be scaled. As shown in Table 4, this amount of power is more than enough to meet the electricity demand of the mill, the electricity infrastructure demand (@ approx. 11\% of the generated electricity) and deliver potential supply to 2060 domestic users within a notional $10 \mathrm{~km}$ radius of the mill (the notional $10 \mathrm{~km}$ radius of the mill was chosen to minimize the electricity transmission and distribution losses).

Table 4. Total electricity annual demand potentially suppliable by case study PO mill generation (2014)

\begin{tabular}{lc}
\hline Power Users & Demand (MWh) \\
\hline $\begin{array}{l}\text { PO Mill operational demand } \\
\text { Household demand (within } \quad \text { 10km }\end{array}$ & 99 \\
radius) & 9,012 \\
Power Plant and infrastructure demand & 1,656 \\
\hline Total Demand & $\mathbf{1 0 , 7 6 7}$ \\
\hline PO Mill Potential Supply & $\mathbf{1 5 , 0 5 9}$ \\
\hline
\end{tabular}

In this analysis $4292 \mathrm{MWh}$ of unused capacity remain after supplying the total demand. This can be used either as a very comfortable reserve margin, despatched to local storage or could be utilised to supply more domestic users beyond our notional $10 \mathrm{~km}$ radius of the $\mathrm{PO}$ mill

\subsection{Environmental impact savings}

The amount of GHG and other gaseous emissions from electricity generation in Malaysia can be calculated from the following equation:

$$
\mathrm{EM}_{\mathrm{i}}=\mathrm{EP}_{\mathrm{i}}\left(P E_{i}^{1} \times E M_{p}^{1}+P E_{i}^{2} \times E M_{p}^{2}+P E_{i}^{3} \times E M_{p}^{3}+\ldots \ldots+P E_{i}^{n} \times E M_{p}^{n}\right)
$$

where:

$\mathrm{EM}_{\mathrm{I}}$ Total emission for a unit of electricity generation

$\mathrm{EP}_{\mathrm{i}}$ Electricity production in year $i$ 
$P E_{i}^{n} \quad$ Percentage of electricity generation in year $i$ of fuel type $n$

$E M_{p}^{n}$ Fossil fuel emission for a unit electricity generation of fuel type $\mathrm{n}$

The amount of emission is a function of the total energy consumption, the fuel mix and the fuel emission factor for each unit of electricity generation [11]. In 2013, 112,358 GWh electricity was generated in Peninsular Malaysia from a mixture of 34\% coal, 58\% gas and $9 \%$ hydro. This mix emitted nationally 78.7 mega-tonnes of $\mathrm{CO}_{2,} 0.6$ mega-tonnes of $\mathrm{SO}_{2}$ and 0.3 mega-tonnes of $\mathrm{NO}_{\mathrm{X}}$.

If the $9012 \mathrm{MWh}$ of annual demand from the 2620 domestic users within the case study $10 \mathrm{~km}$ radius (see Table 4) is supplied from the local PO mill and so taken 'off grid', then over 6000 tonnes of $\mathrm{CO}_{2}$ and other emissions can be avoided from the no longer needed fossil fuel usage for that amount of central generation (Table 5).

Table 5. Impact category reduction

\begin{tabular}{lc}
\hline Impact Category & $\begin{array}{c}\text { Potential environmental impact reduction } \\
\text { per annum from avoided fossil fuel use by } \\
\text { proposed PO mill generation (tonnes/year) }\end{array}$ \\
\hline Global Warming $\left(\mathrm{kg} \mathrm{CO}_{2 \mathrm{e}}\right)$ & 6378 \\
Acidification $\left(\mathrm{SO}_{2 \mathrm{e}}\right)$ & 45 \\
Urban Smog $(\mathrm{NOxe})$ & 21 \\
\hline
\end{tabular}

Under CDM, a reduction of 1 tonne of $\mathrm{CO}_{2}$ emission is equivalent to 1 tonne of Certified Emission Reduction (CER) which can be sold to add to the cash flow of the mill. It could also potentially be used to offset $\mathrm{CO}_{2}$ emissions elsewhere in the Malaysian economy to support the national carbon reduction target. Full analysis of the GHG and other emission balances in order to characterise the net overall balance of emissions savings from PO mill generation vs central generation is currently in progress and will take account of emission factors for various PO mills and diverse technology options.

\section{Conclusion}

Our early results indicate that a decentralized, renewable electricity supply to the Malaysian grid based on PO mill residues would offer benefits in terms of energy security, mitigation of GHG and other emissions from fossil fuel-based generation and as an approach to manage biomass residues at PO mills. The adoption of PO mill residues for electricity generation in Malaysia would help to reduce dependency on, and depletion of, fossil resources whilst simultaneously adding value to currently underutilised Malaysian renewable resources. This resource management and optimization approach would intensify the role of the PO mills in Malaysia's infrastructure and holds potential to contribute positively towards improved global sustainability.

\section{Acknowledgements}

We are especially grateful to the cooperation of the Bell Sri Lingga PO mill at Kuala Linggi, Melaka and the Tenaga Nasional Masjid Tanah Branch Office for provision of data and for their advice and insights. The research was conducted as part of a $\mathrm{PhD}$ programme for Ida Fahani Md Jaye in the Centre for Environmental Strategy, University of Surrey, Guildford, UK with grateful acknowledgement for financial support from Majlis Amanah Rakya (MARA), a government agencies under the Ministry of Rural \& Regional Development.

\section{References}

[1] Sharliza N, et al., Projection of $\mathrm{CO}_{2}$ Emissions in Malaysia, 1-8.

[2] Rahim K.A. Towards low carbon economy via carbon intensity reduction in Malaysia, 2014; 5(16):123-133.

[3] Muis ZA, et al., Optimal planning of renewable energy-integrated electricity generation schemes with $\mathrm{CO}_{2}$ reduction target. Renewable Energy, 2010; 35(11):2562-2570.

[4] Abdullah N, Sulaiman F. The oil palm wastes in Malaysia. Biomass Now - Sustainable Growth and Use, 2013:75-100. 
[5] Foo-Yuen N, Foong-Kheong Y, Yusof BK. A renewable future driven with malaysian palm oil-based green technology. Journal of Oil Palm \& The Environment, 2011:1-7.

[6] Mun TK, Coach T. Development of Malaysia Biomass Industry Linking to Global Value Chain, 2011.

[7] Map of Peninsular Malaysia [Online]. Available: http://www.gostudymalaysia.com.my/living- in-malaysia/malaysias-regions

[8] Map of Melaka [Online]. Available: http://www.mymalaysiabooks.com/images/maps/country_states/melaka_map.jpg

[9] National Biogas Implementation (EPP 5), Biogas Capture and CDM Project Implementation for Palm Oil Mill [Online]. Available: http://www.mpob.gov.my/images/stories/pdf/2014.2014_nkea.pdf

[10] National Key Economic Area (NKEA) Chapter 9 (Palm Oil) [Online]. Available: http://www.mpob.gov.my/images/stories/pdf/NKEA_-_Chapter_9_Palm_Oil.pdf

[11] Mahlia TMI. Emissions from electricity generation in Malaysia. Renewable Energy, 2002; 27(2):293-300. 